\title{
First record of larvae of Chironomidae (Insecta, Diptera) as prey of Temnocephala sp. (Platyhelminthes, Temnocephalidae), an ectosymbiont on larvae of Corydalidae (Megaloptera)
}

\author{
Susana Trivinho-Strixino ${ }^{1,3}$, Fabio Laurindo da Silva² \& Francisco Valente-Neto ${ }^{2}$
}

\begin{abstract}
${ }^{1}$ Laboratório de Ecologia de InsetosAquáticos, Departamento de Hidrobiologia, Universidade Federal de São Carlos, Caixa Postal 676, 13565-905 São Carlos-SP, Brazil.

${ }^{2}$ Programa de Pós-Graduacão em Ecologia e Recursos Naturais, Universidade Federal de São Carlos, CEP 13565-905, São Carlos, São Paulo, Brazil. ${ }^{3}$ Corresponding author. strixino@ufscar.br
\end{abstract}

\begin{abstract}
First record of larvae of Chironomidae (Insecta, Diptera) as prey of Temnocephala sp. (Platyhelminthes, Temnocephalidae), an ectosymbiont on larvae of Corydalidae (Megaloptera). This study constitutes the first record of Temnocephala Blanchard, an ectosymbiont on Corydalidae, as a possible predator of chironomid larvae. Twenty-eight Corydalidae larvae (Corydalus and Protochauliodes) were examined under stereomicroscopic in search for Temnocephala and Chironomidae larvae, of which five megalopteran larvae had 24 Temnocephala sp. associated. Furthermore, eight of these Temnocephala worms had chironomid larvae in their gut contents, an interaction previously unknown. Gut content analyses revealed Corynoneura as the commonest chironomid, but larvae of Larsia, Rheotanytarsus and Tanytarsus were recorded as well. This study included Corydalus and Protochauliodes as hosts for Temnocephala, which might be important for this worm dispersion and population dynamics.
\end{abstract}

KEYWORDS. Commensalism; Corydalus; predation; Protochauliodes.

RESUMO. Primeiro registro de larvas de Chironomidae como presas de Temnocephala sp. (Platyhelminthes, Temnocephalidae), um ectosimbionte de larvas de Corydalidae (Maegaloptera). Este estudo constitui o primeiro registro de Temnocephala Blanchard (Platyhelminthes, Temnocephalidae), um ectosimbionte em larvas de Megaloptera, como um possível predador de larvas de Chironomidae. Vinte e oito larvas de Corydalidae (Corydalus e Protochauliodes) foram examinadas sobre estereomicroscópio na busca por Temnocephala e larvas de Chironomidae, das quais cinco larvas de Megaloptera continham 24 Temnocephala sp. associadas. Além disso, oito Temnocephala possuíam em seu conteúdo estomacal larvas de Chironomidae, uma interação desconhecida anteriormente. A análise do conteúdo estomacal revelou Corynoneura como o quironomídeo mais abundante, e também algumas larvas de Larsia, Rheotanytarsus e Tanytarsus. Este estudo inclui Corydalus e Protochauliodes como hospedeiros de Temnocephala, os quais podem ser importantes para a dispersão e dinâmica populacional desses vermes.

PALAVRAS-CHAVE. Comensalismo; Corydalus; predação; Protochauliodes.

Interactions between organisms, such as competition and predation, have been related as factors that regulate communities (Ricklefs 1987). However, interactions, such as commensalism, have been briefly described and still require further investigation, as indicated by Holomuzki et al. (2010).

In this context, Temnocephala species (Platyhelminthes) have been recorded associated with invertebrate and vertebrate hosts, including insects (Amato \& Amato 2005; Amato et al. 2007; Vianna \& de Melo 2002), molluscs (Damborenea 1998; Seixas et al. 2010), crustaceans (Damborenea 1998) and turtles (Volonterio 2010). As for temnocephalan-host associations, interactions between chironomids and their host have been recorded involving a great array of animals (Roque et al. 2004; Marques et al. 2008), mainly insects, such as megalopteran larvae (Callisto et al. 2006).

The interaction between temnocephalans and megalopteran larvae is poorly known. Furthermore, relationships between temnocephalan worms and chironomid larvae on megalopteran hosts have never been investigated. In this context, this study records for the first time Chironomidae larvae being preyed by Temnocephala, an ectosymbiont on Corydalidae.

Twenty-eight Corydalidae larvae (Corydalus and Protochauliodes) were examined under stereomicroscope in search for Temnocephala worms (egg, young and adult) and Chironomidae larvae associated. Five Corydalidae larvae from two second order streams, located in a preserved area of Cerrado formation municipality, and other 23 larvae (21 Corydalus and 2 Protochauliodes) from Reference Collection of the Laboratório de Ecologia de Insetos Aquáticos, Universidade Federal de São Carlos (LEIA/UFSCar) were carefully analyzed during this research.

Temnocephala specimens were stained with carmineacetoalumen, dehydrated in ethanol, and mounted in Euparal 
before the gut content could be analyzed. Due to the fact that the temnocephalan worms have a rather transparent cuticle, gut contents were examined under a microscope.

Twenty-four temnocephalans were found associated with five megalopteran larvae, this is the first record of such an occurrence (Fig. 1). It could be argued that megalopteran larvae are one of the most suitable insect host groups, together with Plecoptera, Ephemeroptera and Odonata, because they are large with free-living and cryptic benthic species with intermediate mobility (de la Rosa 1992; Tokeshi 1999; Roque et al. 2004).

Moreover, eight temnocephalans had chironomid larvae in their gut contents (Figs. 2-4), interaction previously unknown. Gut content analyses revealed that the most abundant chironomid taxon was Corynoneura, but larvae of Larsia, Rheotanytarsus and Tanytarsus, were recorded as well. Like- wise, Corynoneura was the most abundant and frequent chironomid larvae on megalopteran larvae body, as found by Callisto et al. (2006), i.e., Corynoneura is the most available larvae for Temnocephala. It is noteworthy that we found two megalopteran larvae harbored both Corynoneura larvae and temnocephalan worms.

On the other hand, we found Rheotanytarsus in low abundance and frequency associated with megalopteran larvae. This result differs from de la Rosa (1992) study for Costa Rican streams, which found Rheotanytarsus living on Corydalidae larvae at rather high rates. Larsia was also found in low abundance and frequency. Not a single Tanytarsus larva was found on this host. The interactions between Larsia and Tanytarsus with insect hosts are not well known yet.

Some authors suggested that the association between chironomid larvae and megalopteran hosts might benefit the
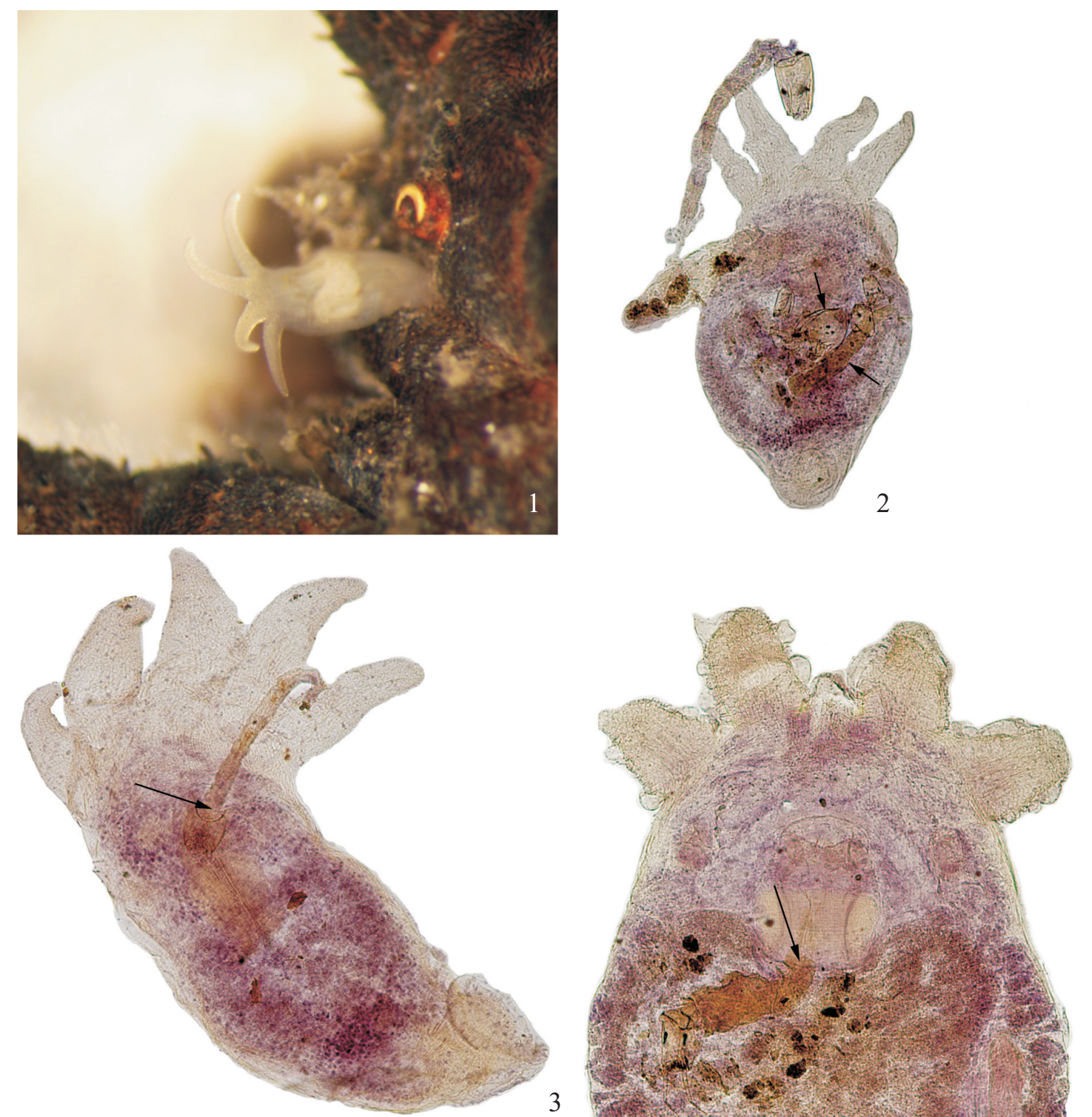

Figs. 1-4. Temnocephala sp. 1. Temnocephala sp. associated to a Corydalus larva. 2-4. Chironomid larvae in the gut content of Temnocephala sp. 
chironomids by improving feeding opportunity, increasing mobility, providing protection from disturbances, and decreasing predation risks (de la Rosa 1992; Tokeshi 1995; Roque et al. 2004). However, the present study provides evidence that the chironomid larvae might be predated by Temnocephala, both associated with megalopteran larvae body. In other words, Temnocephala and chironomid larvae have the same association with megalopteran larvae and Temnocephala could takes advantage of it by preying on chironomids.

In summary, this study included Corydalus and Protochauliodes as new hosts for Temnocephala, which may be important for its dispersion and population dynamics. Moreover, we suggest a new predator prey relationship between Temnocephala and chironomid larvae, both associated with Megaloptera hosts. Thus, the argument currently reported of decreasing predation risk of chironomid larvae when they are associated with insect host might be better studied for understanding the real benefits of this association for chironomids.

\section{ACKNOWLEDGEMENTS}

Thanks are due to Nathan Gilbert Viets for checking the text and for providing helpful comments. This work was partly financed by the Brazilian Council for Scientific and Technological Development (CNPq).

\section{REFERENCES}

Amato, J. F. R. \& S. B. Amato. 2005. New species of Temnocephala Blanchard (Platyhelminthes, Temnocephalida) ectosymbiont on giant water bugs, Belostoma spp. (Hemiptera, Belostomatidae) from southern Brazil. Revista Brasileira de Zoologia 22: 107-118.

Amato, J. F. R.; S. A. Seixas \& S. B. Amato. 2007. A new species of Temnocephala Blanchard (Platyhelminthes, Temnocephalida) ectosymbiont on creeping water bugs, Cryphocricos granulosus De Carlo (Hemiptera, Naucoridae) from southern Brazil. Revista Brasileira de Zoologia 24: 1043-1051.
Callisto, M.; M. D. C. Goulart; P. Moreno, \& R. P. Martins. 2006. Does predator benefit prey? Comensalism between Corynoneura Winnertz (Diptera, Chironomidae) and Corydalus Latreille (Megaloptera, Corydalidae) in Southeastern Brazil. Revista Brasileira de Zoologia 23: $569-572$

Damborenea, M. C. 1998. Distribution patterns of Temnocephalids commensal with Crustacea and Mollusca from Argentina. Hydrobiologia 383: 269274.

de la Rosa, C. L. 1992. Phoretic associations of Chironomidae (Diptera) on Corydalidae (Megaloptera) in northwestern Costa Rican streams. Journal of the North American Benthological Society 11: 316-323.

Holomuzki, J. R.; J. W. Feminella \& M. E. Power 2010. Biotic interactions in freshwater benthic habitats. Journal of the North American Benthological Society 29: 220-244.

Marques, T. S.; B. O. Ferronato; I. Guardia; A. L. B. Longo; S. TrivinhoStrixino; J. Bertoluci \& L. M. Verdade. 2008. Primeiro registro de larvas de Chironomus inquinatus Correia, Trivinho-Strixino \& Michailova (Diptera, Chironomidae) vivendo no casco do cágado Phrynops geoffroanus Schweigger (Testudines, Chelidae) na região Neotropical. Biota Neotropica 8: 1-3.

Ricklefs, R. E. 1987. Community diversity: relative roles of local and regional processes. Science 235: 167-171.

Roque, F. de O.; S. Trivinho-Strixino; M. Jancso \& E. N. Fragoso. 2004. Records of Chironomidae larvae living on other aquatic animals in Brazil. Biota Neotropica 4: 1-9.

Seixas, S. A.; J. F. R. Amato \& S. B. Amato. 2010. Redescription of Temnocephala inheringi (Platyhelminthes, Temnocephalida) based on specimens from Pomacea canaliculata (Mollusca: Ampullariidae) of the state of Rio Grande do Sul, Brazil: the possible type host and type locality. Zoologia 27: 245-257.

Tokeshi, M. 1995. Species interactions and community structure, p. $297-$ 335. In: P. D. Armitage, P. S. Cranston \& L. C. V. Pinder (eds.). The Chironomidae: The biology and ecology of non-biting midges. London, Chapman \& Hall, 588 p.

Tokeshi, M. 1999. Species coexistence: ecological and evolutionary perspectives. Oxford, Blackwell Science, $454 \mathrm{p}$.

Vianna, G. J. C. \& A. L. de Melo. 2002. Aquatic Heteroptera as host of Temnocephala Blanchard (Platyhelminthes: Temnocephalidae) in Minas Gerais, Brazil. Lundiana 3: 151-153.

Volonterio, O. 2010. Two new species of Temnocephala (Platyhelminthes, Temnocephalida) from the South American Snake-Necked Turtle Hydromedusa tectifera (Testudines, Chelidae). Zoological Science 27: 965-970. 